\title{
Passenger train storage system using structural materials
}

\author{
Marilena Stoica ${ }^{1}$, Lucian $\mathrm{Cucu}^{2}$, Gina Florica Stoica $^{3}$ and Radu Mircea Carp-Ciocardia ${ }^{4}$
}

1,2,3,4 University Politehnica of Bucharest, Machine Elements Department, Bucharest, Romania

\begin{abstract}
The structural materials remain a challenge for the development of composite passenger train storage system PTSS, especially when composite materials are assembled. The challenge increase when structural materials must be recycled, in aspect of eco-efficiency. The aim of this paper it's the research of these two aspects with applicability for the passenger train storage.
\end{abstract}

\section{Problem statement}

The structure of a passenger train storage system has two main functions, to hold the components and peripherals involved in the train car and to grow the ergonomic of the luggage space.

According to several studies [1], a passenger train car must be optimized for access, storage and comfort for a certain time frame to achieve the ergonomic standards of the European Union. In this paper, we have made a research about the possibility of modification a passenger train car by moving the storage spaces on the exterior of the train. The storage system, will be on the exterior of the train car, based on modular systems architecture.

Taking into consideration the big number of train cars and the recycled/benefit ratio in the European Union, it is reasonable for the structure to be with materials recycled.

The structure of a passenger train storage system plays a key role on the final functionalities of the productivity and accuracy. There are many studies which explain different strategies that can be employed to conceive and produce machine structures that achieve appropriate values of productivity and accuracy by means of good thermal and vibrations behavior combined with low amounts of movable masses.

\section{Theoretical background}

The optimization of the passenger train storage system structures represents an important task for designers. The design for passenger train storage systems was made considering reduction of the mass for each component involved, to preserve the same mechanical properties for the good functionality of the system. Considering an easier system, with a lower environmental impact, we designed an exoskelet to fix the system

The components of the systems are shown in figure 1. The material of the capsule support structure is a carbon fiber reinforced polymer and for the capsule itself is aluminum.

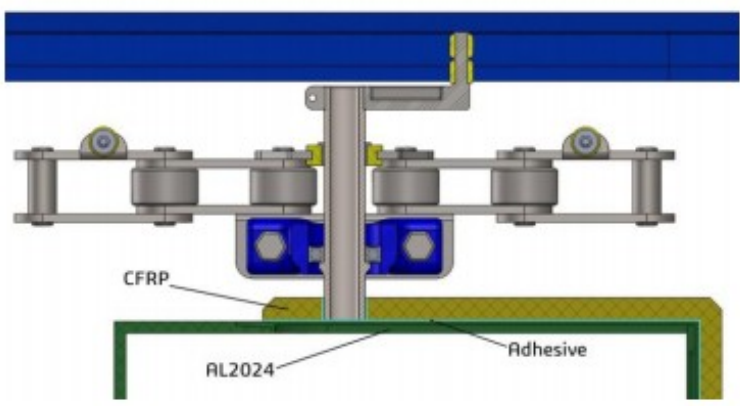

Fig. 1. Storage capsule components 


\section{Structural materials}

When designing structural components, to achieve eco-efficient, accurate and productive machines, the materials to be used play a key role in the final properties of the components and the machines in which they are integrated. Structural materials movable mass has a decisive influence in moments of inertia, static and dynamic stiffness and also in the modal and thermal properties of the machine.

The material chosen is carbon fiber composites, of the type prepreg carbon/ epoxy.

This form of composite fabrication begins with the pre-impregnation of reinforced materials with a resin. Epoxy resins have very good properties and it was chosen to be compatible with the adhesive. Carbon fiber composite profiles are superior materials for fast moving parts in machines because they're very high stiffness to weight ratio. Assembly ensures load transfer from one piece to another, and therefore the assembly technique becomes an important factor. There are many methods of joining, but generically the three major structural assembly techniques are welding, bonding and bolting. An example is the assembly of two composite parts for which the bonding is widespread. Furthermore, it is possible to combine these different modes of assembly.

Table 1. Components material of the assembly

\begin{tabular}{|c|c|c|}
\hline $\begin{array}{c}\text { Carbon } \\
\text { Fiber } \\
\text { Reinforced } \\
\text { Plastic }\end{array}$ & $\begin{array}{c}\text { Piece } \\
\text { aluminiu } \\
2024\end{array}$ & $\begin{array}{c}\text { Adhesiv } \\
\text { Scotch Weld } \\
3 \mathrm{M} 2216 \\
\text { Grey }\end{array}$ \\
\hline $\begin{array}{c}\mathrm{E}=48 \\
\mathrm{GPa}\end{array}$ & $\mathrm{E}=68 \mathrm{GPa}$ & $\mathrm{E}=350 \mathrm{MPa}$ \\
\hline $\begin{array}{c}\mathrm{Rp} 0.2=600 \\
\mathrm{MPa}\end{array}$ & $\begin{array}{c}\mathrm{Rp} 0.2=290 \\
\mathrm{MPa}\end{array}$ & $\mathrm{Re}=15 \mathrm{MPa}$ \\
\hline
\end{tabular}

The structural materials pre-preg with carbon fiber can be recycled using different techniques, the most used are pyrolysis, catalytic conversion processing. With these techniques, are obtaining scraps of material, in special carbon fiber without any resins. Concerning the environmental impact, an issue which concerns the industry, these materials are used until failure with multiple applicability.

Regarding the epoxy matrix recovered during the recycling process, it can be observed that epoxy is less recycled [4]. Based on the proposed formula (equation 1) for the degree of recyclability and index analysis: traction resistance, fiber recovery and matrix recovery, it can be said that the degree of recyclability of the carbon fiber composite material is about $75 \%$.

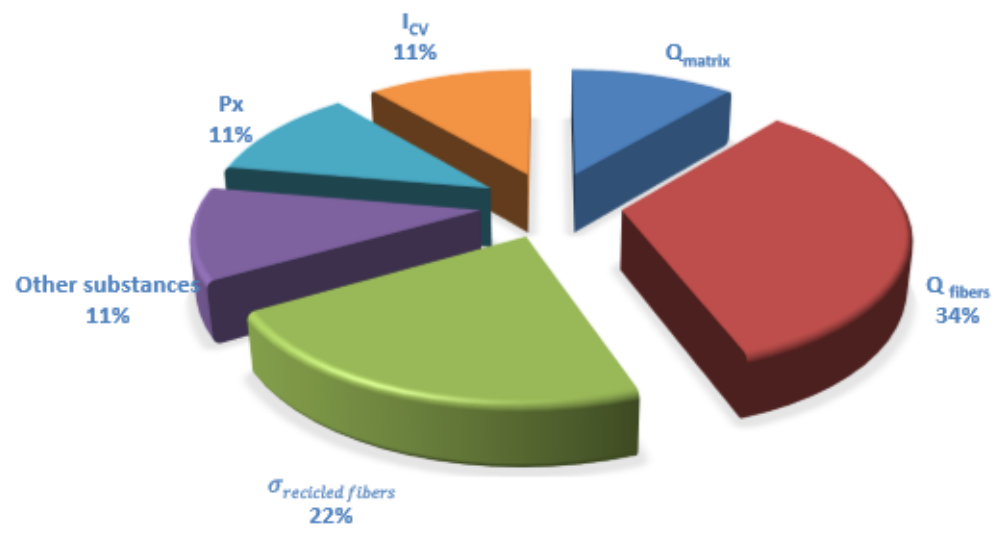

Fig. 2. Recycling CFRP 


\section{$R M=\alpha * Q$ matrix $+\beta * Q$ fibers $+\gamma *$ orecicled_fibers $+\delta * \Sigma$ (other substances) $+\lambda * P x+\theta * I C V(1)$}

$\alpha, \beta, \gamma, \delta, \lambda, \theta$ - coefficients of importance in material recyclability $[1,2]$

$\mathrm{RM}=$ recyclability of fiber composite materials

Qmatrix = the amount of recycled matrix

Qfibers= the amount of recycled fibers

orecicled fibers $=$ admissible stress depending on the material and the recycling mode

$\mathrm{Px}=$ type of recycling process used

$\mathrm{ICV}=$ index for recycled fibers resulting from different stages of the life cycle

\section{Conclusions}

This paper suggests that, a passenger train storage system, using structural materials as a response to perform assessment of the state-of-the-art technology will make the design more competitive and the cost more reasonable.

The type of the assembly is very important for the innovation of the passenger train storage. The choice of materials for a passenger train storage system using structural materials is one of the key factors in determining the final system performance.

Several criteria may be considered, including specific stiffness, homogeneity, easiness of manufacturing and cost.

The eco-efficiency criteria is obtained, by creating the possibility of recycling the component elements of the system. It has been researched, that today, are available a lot of techniques which can obtain the trimmed fiber in a big percentage (almost $80 \%$ ) in the composite material recycling industry.

\section{References:}

1. Neufert and E. a. Peter, Architects' Data, vol. 3, pp. 426-432

2. J. Zulaika, F. J. Campa, New Concepts for Structural Components, Machine Tools for High Performance Machining (2013)

3. S.W. Tsai, HyperComposites: Composites Design in HyperCard (Plane stress and plane strain, 1988) 